\title{
Intestinal Protozoa in Immunosuppression: A Medical Hassle
}

Neha Ballani ${ }^{1}$, Fatima Shujatullah ${ }^{1 *}$, Haris M. Khan ${ }^{1}$, Abida Malik ${ }^{1}$, MohdAshfaq S.M Ali ${ }^{2}$ and Parvez A. Khan ${ }^{1}$

${ }^{1}$ Department of Microbiology, J.N. Medical College, AMU, Aligarh, India

${ }^{2}$ Department of Pediatrics, J.N. Medical College, AMU, Aligarh, India

\begin{abstract}
Introduction: Immunity forms the backbone of our very existence and opportunistic infections have plagued the immunosuppressed since long. A significant morbidity and mortality is attributable to intestinal parasitosis in the immunocompromised population.
\end{abstract}

Objectives: This study aims to study the prevalence of intestinal protozoa in various immunosuppressed groups and to correlate degree of immunosuppression with protozoal infections.

Material and Methods: The study was conducted on 400 patients divided into 4 groups: Group I (HIV patients), Group II (patients on chemotherapy/chemotherapy and radiotherapy for various malignancies), and Group III (diabetes patients) and Group IV included children presenting with diarrhea. Group I, II and III included patients with and without gastrointestinal symptoms. Stool samples were investigated microscopically for cysts/trophozoites after concentration with formol-ether method. lodine wet mount and Modified acid fast staining methods were used.

Result: Intestinal protozoa were detected in 40.75\% (163/400); more commonly in patients with higher degree of immunosuppression (CD4 count $<200 / \mu \mathrm{l}$ in HIV patients: $62.5 \%$, malignancy patients on both chemotherapy and radiotherapy: $71.1 \%$, higher levels of $\mathrm{HbA1c}>7$ : $95.3 \%$ in diabetics and moderate to severe malnutrition: $61.8 \%$. Most common protozoa associated was Cryptosporidium in 66 patients $(40.5 \%)$ followed by, Entamoeba histolytica in $48(29.4 \%)$, Giardia lamblia in 35 (21.5\%), Isosporabelliin 9 (5.5\%), Blastocystis hominis in 4 (2.5\%), Cyclospora cayetenensis in $1(0.61 \%)$.

Conclusion: High prevalence of intestinal protozoa was seen in all groups of immunosuppressed patients and a significant association seen between degree of immune suppression and protozoal infection. Focus needs to be on routine screening of all immunosuppressed patients and their immune reconstitution.

Keywords: Intestinal protozoa; Immunosuppressed

\section{Introduction}

With an enormous increase in the immunosuppressed population owing to the HIV pandemic throughout the world, incidence of malignancies being continuously on the rise, more aggressive immunosuppressive therapies for organ transplants and the number of people affected by diseases like diabetes and tuberculosis ever increasing, the panacea remains immune reconstitution of these patients and thorough screening to prevent various opportunistic infections. Among different pathogens causing gastrointestinal infection, parasites are likely to have significant role as primary cause of co-morbidity of diarrhea in the immunocompromised.

Previous studies on immunocompromised populations (HIV, malignancy, and others), which mainly comprised adults, reported variable prevalence $(2-50 \%)$ of intestinal parasitic infections with different etiologic patterns $[1,2]$. This is the first study done in India to the best of our knowledge that includes various immunocompromised patients of different age groups and correlates the level of immunosuppression with the opportunistic protozoal infections.

\section{Material and Methods}

A retrospective study was conducted at Department of Microbiology, Jawaharlal Nehru Medical College and Hospital, Aligarh, over a period of 1 year. Various groups of immunocompromised patients with or without gastrointestinal symptoms were included in the study; Group I (HIV patients), Group II (patients undergoing chemotherapy/ chemotherapy and radiotherapy for various malignancies), Group III (diabetes patients), Group IV (children presenting with diarrhea with normal/impaired nutritional status). All patients were advised to give three consecutive stool samples. Protozoal infections were diagnosed by examination of stool specimens as fresh wet mounts, formol-ether concentration [3] technique and modified acid fast stain. Fresh and concentrated stool specimens were examined as saline wet mounts and iodine wet mounts [3]. Air dried smears from fresh stool samples were fixed and stained by a modified acid fast stain to detect the coccidian parasites- Cryptosporidium, Isospora and Cyclospora species [4]. E. histolytica was considered as the causative agent when the trophozoite/ cyst suggestive of Entamoeba was identified along with the suggestive signs and symptoms pathognomonic for amoebic dysentery.

Statistical analysis was done using Chi-square test to observe association between degree of immunosuppression and protozoal infection and observed differences in data were considered significant if $\mathrm{p}<0.05$ was obtained.

\section{Results}

Stool samples from a total of 400 patients; 100 in each group were examined for the presence of protozoa and 50 controls were also included. 48 (48\%) of the HIV positive patients (Group I), 38 (38\%) pa-

*Corresponding author: Dr. Fatima Shujatullah, Department of Microbiology, J.N.Medical College, AMU, Aligarh, India, E-mail: sfatima777@gmail.com

Received March 14, 2012; Accepted April 27, 2012; Published May 03, 2012

Citation: Ballani N, Shujatullah F, Khan HM, Malik A, Ali MSM, et al. (2012) Intestinal Protozoa in Immunosuppression: A Medical Hassle. J Bacteriol Parasitol 3:138. doi:10.4172/2155-9597.1000138

Copyright: @ 2012 Ballani N, et al. This is an open-access article distributed unde the terms of the Creative Commons Attribution License, which permits unrestricted use, distribution, and reproduction in any medium, provided the original author and source are credited. 
tients with malignancy and undergoing chemotherapy or both chemotherapy and radiotherapy (Group II), 43 (43\%) patients with diabetes (Group III) and 34 (34\%) patients in Group IV were infected with intestinal protozoa.

Only $8 \%$ of patients in the control group were infected with protozoa and none was infected with any coccidian parasite. E. histolytica and G. lamblia were found in $10 \%$ and $6 \%$ patients respectively.

In Group I maximum numbers of patients were in the age group $35-40$ years $(39 \%)$ and males $(72 \%)$ were more than females $(28 \%)$. Cryptosporidium sp. was the most common protozoa found in this group (41.7\%). E. histolytica (31.3\%), Giardia lamblia (12.5\%), Isospora belli (12.5\%), Cyclospora (2.1\%) were the other protozoa found. Coccidian parasites were found in $28 \%$ while the non-opportunistic parasites found in $21 \%$ patients.

In group I, this constituted HIV positive patients. All the protozoa were more commonly found in patients with CD 4 count $<200$ cells $/ \mu$ l. Among 48 patients infected with protozoa, 30 (62.5\%) had CD4 count $<200$ cells/ $\mu$ l while $18(37.5 \%)$ patients had CD4 count $>200$ cells/ $\mu \mathrm{l}$ (Table 1).

In Group II, maximum number of patients in this group was in the age group 65-75 years (25\%) and males (63\%) were more than females (37\%). Cryptosporidium sp. (15\%) and E. histolytica (15\%) were the most common protozoa found in this group. Giardia lamblia (5\%) and Isospora belli (3\%) were the other protozoa found.

Table 2 shows the correlation between intestinal protozoal infection and chemotherapy/chemotherapy and radiotherapy. 27 (71.1\%) patients infected with intestinal protozoa were on chemotherapy and radiotherapy while $11(29 \%)$ were on chemotherapy only. Most of the protozoal infections were more common in patients on both chemotherapy and radiotherapy.

In Group III, maximum number of patients in this group was in the age group 50-55 years and 60-65 years (16\%) and males (80\%) were more than females (20\%). Cryptosporidium sp. was the most common protozoa found in this group (25\%). E. histolytica (12\%), Giardia lamblia $(6 \%)$ were the other protozoa found.

\begin{tabular}{|l|c|c|c|}
\hline \multicolumn{1}{|c|}{ Intestinal Protozoa } & CD4 count $\mathbf{2 0 0}$ & CD4count $<\mathbf{2 0 0}$ & Total \\
\hline 1. E. histolytica & $7(46.7)$ & $8(53.3)$ & $15(31.3)$ \\
\hline 2. Giardia lamblia & $2(33.3)$ & $4(66.7)$ & $6(12.5)$ \\
\hline 3. Cryptosporidium $\mathrm{sp.}$ & $7(35)$ & $13(65)$ & $20(41.7)$ \\
\hline 4. Isospora belli & $2(33.3)$ & $4(66.7)$ & $6(12.5)$ \\
\hline 5. Cyclosporacayetenensis & - & $1(100)$ & $1(2.1)$ \\
\hline Total & $18(37.5)$ & $30(62.5)$ & $48(100)$ \\
\hline
\end{tabular}

*Figure within parentheses indicates percentage.

Table 1: Intestinal protozoal Infection in HIV-positive patients with reference to CD4 Count.

\begin{tabular}{|l|l|l|l|}
\hline \multicolumn{1}{|c|}{ Intestinal protozoa } & Chemotherapy & $\begin{array}{c}\text { Chemotherapy+ } \\
\text { Radiotherapy }\end{array}$ & \multicolumn{1}{|c|}{ Total } \\
\hline 1. E. histolytica & $5(33.3)$ & $10(66.7)$ & $15(39.5)$ \\
\hline 2. Giardia lamblia & $4(80)$ & $1(20)$ & $5(13.2)$ \\
\hline 3. Cryptosporidium sp. & $2(13)$ & $13(86.7)$ & $15(39.5)$ \\
\hline 4. Isospora belli. & - & $3(100)$ & $3(7.9)$ \\
\hline Total & $11(29)$ & $27(71.1)$ & $38(100)$ \\
\hline
\end{tabular}

${ }^{*}$ Figure within parentheses indicates percentage

Table 2: Correlation between intestinal protozoal infection and chemotherapy/chemotherapy and radiotherapy.
Table 3 shows the correlation between intestinal protozoal infection and glycosylated hemoglobin (HbA1c).28 (65.1\%) patients infected with intestinal protozoa had glycosylated hemoglobin (HbAlc) between 7-10, 13 (30.2\%) had HbAlc >10, and 2 (4.7\%) had HbA1c $<$ 7.Protozoal infections were more commonly found in patients with $\mathrm{HbA1c} 7-10$ and $\mathrm{HbA1c}>10$.

Group IV had maximum number of patients in the age group 4-6 years (23\%). Males (62\%) were more than females (38\%). 34 (34\%) out of 100 patients in this group were infected with intestinal protozoa. Giardia lamblia was the most common protozoa found (18\%), E. histolytica and Cryptosporidium species were found in $6(6 \%)$ patients each. Blastocystis hominis was also found in 4 patients (4\%).

Table 4 shows association between intestinal protozoal infection and nutritional status. Among the patients found to have intestinal protozoal infection, 8 (47.1\%), 13(43.1\%), 6 (19.4\%), 2 (28.6\%) had PEM Grade I, II, III and IV respectively. Out of the 34 patients infected with intestinal protozoa, $21(61.8 \%)$ had moderate to severe malnutrition.

\section{Discussion}

Human Immunodeficiency Virus (HIV) infection and Acquired Immunodeficiency Syndrome (AIDS) are among the leading causes of infectious disease morbidity and mortality worldwide. India is estimated to have the second largest HIV positive population in the world [5,6], with more than 5.7 million persons living with HIV/AIDS with prevalence in adults of $0.91 \%$. Concomitant infections play a major contributing role in the morbidity associated with HIV/AIDS and thus effective prevention, diagnosis, and management of accompanying infections are critical for improving the health and well-being of people infected with HIV. Among AIDS patients in developing countries, as many as $95 \%$ may have diarrhea [6,7]. In a large proportion of this population, the diarrhea may become prolonged and life-threatening, and chronic diarrhea is an independent marker of poor prognosis in patients with AIDS [8].

Despite the spread of HIV infection in India, and the high prevalence of diarrheal disease, there is little information available on the epidemiology of diarrheal disease among people with HIV infection. In a review of HIV-related Opportunistic Infections (OIs) in northern India, chronic diarrhea was the second most common opportunistic

\begin{tabular}{|l|c|c|c|c|}
\hline \multicolumn{1}{|c|}{ Intestinal protozoa } & HbA1c $<7$ & HbA1c 7-10 & HbA1c >10 & Total \\
\hline 1. E. histolytica & $2(16.7)$ & $7(58.3)$ & $3(25)$ & $12(28)$ \\
\hline 2. Giardia lamblia & - & $3(50)$ & $3(50)$ & $6(14)$ \\
\hline 3. Cryptosporidium $\mathrm{sp.}$ & - & $18(72)$ & $7(28)$ & $25(58.1)$ \\
\hline Total & $2(4.7)$ & $28(65.1)$ & $13(30.2)$ & $43(100)$ \\
\hline
\end{tabular}

*Figure within parentheses indicates percentage.

Table 3: Correlation between intestinal protozoal infection and glycosylated haemoglobin (HbA1c)

\begin{tabular}{|l|c|c|c|}
\hline Nutritional status & Positive & Negative & Total \\
\hline Normal nutrition & $5(33.3)$ & $10(66.7)$ & $15(15)$ \\
\hline PEM Grade I & $8(47.1)$ & $9(53)$ & $17(17)$ \\
\hline PEM Grade II & $13(43.3)$ & $17(56.7)$ & $30(30)$ \\
\hline PEM Grade III & $6(19.4)$ & $25(80.6)$ & $31(31)$ \\
\hline PEM Grade IV & $2(28.6)$ & $5(71.4)$ & $7(7)$ \\
\hline Total & $34(34)$ & $66(66)$ & 100 \\
\hline
\end{tabular}

*Figure within parentheses indicates percentage.

Table 4: Association of Intestinal protozoal infection with nutritional status. 
infection encountered [9]. Parasitic infections with Isospora belli, Entamoeba histolytica, and Cryptosporidium sp. have been reported as being among the most frequently identified organisms in India $[9,10]$ but few studies have systematically examined the etiology of diarrhea in this population. Only a few studies regarding the prevalence of intestinal parasites and their association with diarrhea of HIV- infected patients are available from North India at present.

Our study was done on $100 \mathrm{HIV}$ positive patient attending ART clinic of JNMCH. Enteric protozoa were detected in 48 (48\%) stool samples and Cryptosporidium (20\%) was the most frequently encountered pathogen in the study population followed by E. histolytica (15\%). Both Isospora and Giardia lamblia were found in $6(6 \%)$ patients and Cyclospora in $1(1 \%)$ patient. Coccidian parasites were found in $27 \%$ while the non-opportunistic parasites found in $21 \%$ patients. E. histolytica and G. lamblia were found in $15 \%$ and $6 \%$ patients respectively.

Difference in the incidence of intestinal protozoal parasitic infection reported by different workers can be attributed to the difference in geographical distribution of parasites, sanitary practices and different selection of cases. Various studies from India and other countries have reported a high prevalence of intestinal parasite, ranging from 25 to 60 percent [11-19].

The world wide prevalence of enteric protozoa in various populations of the immunosuppressed has been shown by Stark et al. [20]. The coccidian parasites (Cryptosporidium sp., Isospora belli, Cyclospora) are foremost among the enteric parasites in these patients [18]. In India, there have been reports from mid-1990s on the prevalence of symptomatic cryptosporidiosis in HIV infected adults from different parts of the country, ranging from as low as $0.7 \%$ to as high as $81 \%$ [11] and $1.5 \%$ and $13.3 \%$ from other countries [15]. Earlier studies [14,21] from north India have also found Cryptosporidium sp. to be the most common parasite while the prevalence of Isospora belli was found to be much lower. Studies from South India [22,23] have reported a higher prevalence of Isospora belli than Cryptosporidium sp. The low prevalence of Isospora could be due to the frequent use of TMP/SMX as prophylaxis for opportunistic infections. Isosporais infrequently associated with diarrhea due to AIDS in the USA and Europe (about $2 \%)$, but is commonly isolated in patients with AIDS and chronic diarrhea in Brazil (9.9\%), Zaire (12\%), Zambia (16\%), and Haiti (12\%) [24]. Detection rate of Cyclospora in this study found to be $1.0 \%$ in HIV patients which correlates with the studies done in Chennai $(0.6 \%)$ [23] and in Gujrat (1\%) [17]. Higher rates of infection by Cyclospora have been reported by Mohandas et al. [14] (3.3\%) and Soave R [25] (11\%). Cyclospora is common in Haiti (11\%), but only rarely detected in US and Tanzanian patients with AIDS and chronic diarrhea $(<1 \%)$ $[24,26]$. Among the non opportunistic pathogens E. histolytica / E. dispar seemed to contribute significantly as shown earlier [15,19,21,27]. Earlier studies $[14,28]$ have reported rates of infection with $G$. lamblia between 1-11\%. Mohandas et al. [14] reported that Giardias is does not occur in greater frequencies in HIV- positive patients than in HIVnegative individuals. The reported prevalence of non opportunistic parasites varied from 5-30 per cent in HIV infected patients [29,30].

CD4counts play an incredibly important role in the presentation of diarrhea as well as in the control of protozoa in HIV-infected individuals. For example, chronic diarrhea is typically associated with lower CD4 counts than acute diarrhea. In addition, at counts of less than 200, $\mathrm{HIV}$-infected patients are at risk from specific opportunistic protozoan pathogens which are usually unable to establish infection in immunocompetent hosts $[31,32]$. The study group consisted of 50 patients with CD 4 count $>200$ cells/ $\mu$ l and 50 patients with CD 4 count $<200$ cells/ $\mu \mathrm{l}$. In our study, all the protozoa were more commonly found in patients with CD4 count $<200$ cells/ $\mu$ l and the correlation between CD4 cell count and intestinal protozoal infection was found to be significant $(\mathrm{p}<0.05) .30(62.5 \%)$ patients infected with protozoa had CD4 count $<$ 200 while 18 (37.5\%) had CD4 count $>200$. This is in concordance with the findings in the study by Kulkarni et al. [19]. Several other studies have reported the correlation between CD4 count and diarrhea in HIV positive patients and this reflects a compromised immune system with increased risk of disease $[33,34]$.

Due to easy availability of HAART in developed nations, there has been a reduction in the prevalence of intestinal parasites in AIDS patients. At higher CD4 T-cell levels, generally, spontaneous clearing of the parasite takes place. In resource settings like ours, patients usually go undiagnosed for long periods and present late in the course of the disease. Consequently, the patients usually present with profound, persisting and multiple intestinal infections and a low CD4 T cell counts.

Unfortunately, our knowledge of the human immune system and the way it interacts with parasites is much more limited, despite the recognition that enteric parasites are commonly associated with the onset of diarrhea in IS patients.

Thus, we also included patients with malignancy and diabetes in our study to comprehend the pattern of protozoal infections in these immunocompromised patients and correlate it with level of immunosuppression in this group.

Group II consisted of patients with malignancy. Among 100 patients $38(38 \%)$ patients had intestinal protozoal infections. Cryptosporidium sp. (15\%) and E. histolytica (15\%) were the most common protozoa found in this group. Giardia lamblia (5\%) and Isospora belli (3\%) were the other protozoa found. E. histolytica and G. lamblia were found in 15\% and 5\% patients respectively. 27 (71.1\%) patients infected with intestinal protozoa were on chemotherapy and radiotherapy while 11 (29\%) were on chemotherapy only. Most of the protozoal infections were more common in patients on both chemotherapy and radiotherapy and the correlation was found to be significant $(\mathrm{p}<0.05)$

$43(43 \%)$ patients with diabetes in group III had intestinal protozoal infections. Cryptosporidium sp. was the most common protozoa found in this group (25\%). E. histolytica (12\%), Giardia lamblia (6\%) were the other protozoa found. 28 (65.1\%) patients infected with intestinal protozoa had glycosylated hemoglobin (HbAlc) between 7-10, 13 (30.2\%) had HbA1c $>10$, and $2(4.7 \%)$ had HbAlc $<7$.Protozoal infections were more commonly found in patients with HbAlc 7-10 and $>$ 10 , however the correlation was not significant.

Several studies have been conducted on immunosuppressed patients like those with haematological malignancies, PEM, patients receiving immunosuppressive drugs for organ transplants or cancers, patients undergoing dialysis and those having diabetes. These patients have been found to be at significant risk of severe cryptosporidiosis, infection with I. belli, Cyclospora [35-39]. There are reports of three patients with diabetes suffering chronic diarrhea due to cryptosporidiosis $[40,41]$. In malignant disease, there are studies which show the risk of severe cryptosporidiosis being limited largely to children with acute leukemia and lymphoma [41]. Although there are relatively few studies of cryptosporidiosis in patients with primary immunodeficiencies, it would appear that the risk is largely limited to those individuals with impaired T-cell function $[42,43]$. 
Citation: Ballani N, Shujatullah F, Khan HM, Malik A, Ali MSM, et al. (2012) Intestinal Protozoa in Immunosuppression: A Medical Hassle. J Bacteriol Parasitol 3:138. doi:10.4172/2155-9597.1000138

\section{Conclusion}

Our study highlights the magnitude of protozoal infections in various groups of immunosuppressed patients with or without diarrhea and also a profound association with the level of immunosuppression. The rationale behind preventing protozoal gastrointestinal infections and reducing morbidity caused by them in the immunocompromised should be focused on routine screening of these patients and high index of suspicion for the enteric protozoa as these have been proved to be the commonly implicated pathogens time and again. Empirical therapy sans knowledge of etiology and pattern of infection in a particular population defers proper cure and increases burden on the health care sector. Further such studies done on larger sample size from different regions of the country will give direction to the efforts of the physician.

\section{References}

1. El-diffrawy M, Neanaa H, Eissa M, Sadaka H, Nomir A (2002) Study of parasitic infections in immunocompromised patients in Haematology Department at Main University Hospital, Alexandria. Exp Pathol Parasitology 10: 85-92.

2. Botero JH, Castaño A, Montoya MN, Ocampo NE, Hurtado MI, et al. (2003) A preliminary study of the prevalence of intestinal parasites in immunocompromised patients with and without intestinal manifestations. Rev Inst Med Trop Sao Paulo 45: 197-200.

3. Garcia LS, Bruckner DA (1993) Macroscopic and microscopic examination of fecal specimens. (2ndedn), American Society for Microbiology, Washington, D.C.

4. Sehgal R, Mahajan RC, Thapa BR, Ganguly NK (1989) Cryptosporidiosis causing chronic diarrhea in a child. Indian J Pediatr 56: 145-147.

5. Joint United Nations Programme on HIVIAIDS (UNAIDS) (2006) 2006 Report on the Global AIDS Epidemic. UNAIDS, Geneva.

6. Guerrant RL, Hughes JM, Lima NL, Crane J (1990) Diarrhea in developed and developing countries: magnitude, special settings and etiologies. Rev Infect Dis 1: S41-S50.

7. Guerrant RL, Bobak DA (2000) Nausea, vomiting and non inflammatory diarrhea. (7thedn), Principles and Practice of Infectious Disease. Harcourt, New York.

8. Lew EA, Poles MA, Dieterich DT (1997) Diarrheal diseases associated with HIV infection. Gastroenterol Clin North Am 26: 259-290.

9. Vajpayee M, Kanswal S, Seth P, Wig N (2003) Spectrum of opportunistic infections and profile of CD4+ counts among AIDS patients in north India. Infection 31: $336-340$.

10. Ajjampur SS, Sankaran P, Kang G (2008) Cryptosporidium species in HIV-infected individuals in India: an overview. Natl Med J India 21: 178-184.

11. Gomez Morales MA, Atzori C, Ludovisi A, Rossi P, Scaglia M, et al. (1995) Opportunistic and non-opportunistic parasites in HIV positive \& negative patients with diarrhea in Tanzania. Trop Med Parasitol 46: 109-114.

12. Weber R, Ledergerber B, Zbinden R, Altwegg M, Pfyffer GE, et al. (1999) Enteric infections and diarrhea in human immunodeficiency virus-infected persons: prospective community-based cohort study. Arch Intern Med 159: 1473-1480.

13. Brink AK, Mahé C, Watera C, Lugada E, Gilks C, et al. (2002) Diarrhea, CD4 counts and enteric infections in a community-based cohort of HIV-infected adults in Uganda. J Infect 45: 99-106.

14. Mohandas, Sehgal R, Sud A, Malla N (2002) Prevalence of intestinal parasitic pathogens in HIV-seropositive individuals in Northern India. Jpn J Infect Dis 55: 83-84.

15. Dwivedi KK, Prasad G, Saini S, Mahajan S, Lal S, et al. (2007) Enteric opportunistic parasites among HIV infected individual: associated risk factors and immune status. Jpn J Infect Dis 60: 76-81.

16. Ramakrishnan K, Shenbagarathai R, Uma A, Kavitha K, Rajendran R, et al. (2007) Prevalence of intestinal parasite infestaton in HIVIAIDS patients with diarrhea in Madurai, South India. Jpn J Infect Dis 60: 209-210.
17. Gupta, M Sinha M, Raizada N (2008) Opportunistic Intestinal Protozoan Parasitic Infection in HIV Positive Patient in Jamnagar, Gujarat. SAARC J Tuber Lung Dis HIVIAIDS 5: 21-24.

18. Gupta S, Narang S, Nunavath V, Singh S (2008) Chronic diarrhoea in HIV patients: prevalence of coccidian parasites. Indian J Med Microbiol 26: 172-175.

19. Kulkarni SV, Kairon R, Sane SS, Padmawar PS, Kale VA, et al. (2009) Opportunistic parasitic infections in HIVIAIDS patients presenting with diarrhea by the level of immunosuppression. Indian J Med Res 130: 63-66.

20. Stark D, Barratt JL, van Hal S, Marriott D, Harkness J, et al. (2009) Clinical Significance of Enteric Protozoa in the Immunosuppressed Human Population. Clin Microbiol Rev 22: 634-650.

21. Sadraei J, Rizvi MA, Baveja UK (2005) Diarrhea, CD4+ cell counts and opportunistic protozoa in Indian HIV-infected patients. Parasitol Res 97: 270-273.

22. Mukhopadhya A, Ramakrishna BS, Kang G, Pulimood AB, Mathan MM, et al (1999) Enteric pathogens in Southern Indian HIV -infected patients with and without diarrhea. Indian J Med Res 109: 85-89.

23. Kumar SS, Ananthan S, Saravanan P (2002) Role of coccidian parasites in causation of diarrhea in HIV infected patients in Chennai. Indian $\mathrm{J}$ Med Res 116: 85-89.

24. Goodgame RW (1996) Understanding intestinal spore forming protozoa: Cryptosporidia, Microsporidia, Isospora and Cyclospora. Ann Intern Med 124: 429441.

25. Soave R (1996) Cyclosporiasis. Clin Infet Dis 23: 429-437.

26. Weber R, Bryan RT, Schwartz DA, Owen RL (1994) Human microsporidial infection. Clin Microbiol Rev 7: 426-461.

27. Attili SV, Gulati AK, Singh VP, Varma DV, Rai M, et al. (2006) Diarrhea, CD4 counts and enteric parasites in a hospital based cohort of HIV-infected patients around Varanasi, India. BMC Infect Dis 6: 39.

28. Janoff EN, Smith PD, Blaser MJ (1988) Acute antibody responses to Giardia lamblia are depressed in patients with AIDS. J Infect Dis 157: 798-804.

29. Lucas SB (1990) Missing infections in AIDS. Trans R Soc Trop Med Hyg 84 34-38.

30. Gumbo T, Sarbah S, Gangaidzo IT, Ortega Y, Sterling CR, et al. (1999) Intestinal parasites in patients with diarrhea and human immunodeficiency virus infection in Zimbabwe. AIDS 13: 819-821.

31. Weber R, Ledergerber B, Zbinden R, Altwegg M, Pfyffer GE, et al. (1999) Enteric infections and diarrhea in human immunodeficiency virus-infected persons: prospective community-based cohort study. Swiss HIV Cohort Study. Arch Intern Med 159: 1473-1480.

32. Navin TR, Weber R, Vugia DJ, Rimland D, Roberts JM, et al. (1999) Declining CD4+ T-lymphocyte counts are associated with increased risk of enteric parasitosis and chronic diarrhea: results of a 3-year longitudinal study. J Acquir Immune Defic Syndr Hum Retrovirol 20: 154-159.

33. Cárcamo C, Hooton T, Wener MH, Weiss NS, Gilman R, et al. (2005) Etiologies and manifestations of persistent diarrhea in adults with HIV-1 infection: a casecontrol study in Lima, Peru. J Infcet Dis 191: 11-19.

34. Becker ML, Cohen CR, Cheang M, Washington RG, Blanchard JF, et al. (2007) Diarrheal disease among HIV-infected adults in Karnataka, India: Evaluation of risk factors and etiology. Am J Trop Med Hyg 76: 718-722.

35. Westerman EL, Christensen RP (1979) Chronic /sospora belli infection treated with co-trimoxazole. Ann Intern Med 91: 413-414.

36. Jayshree RS, Acharya RS, Sridhar H (1996) Isospora belli infectionin a patient with acute lymphoblastic leukaemia in India. J Diarrhoeal Dis Res 14: 44-45.

37. Chieffi PP, Paschoalotti MA, Vergueiro CS, Chiattone CS (2005) Infection by Cryptosporidium sp. in immunocompromised haematological patients. Rev Inst Med Trop Sao Paulo 47: 301-302

38. Helmy MM, Rashed LA, Abdel-Fattah HS (2006) Co-infection with Cryptosporidium parvum and Cyclospora cayetanensis in immunocompromised patients. J Egypt Soc Parasitol 36: 613-627.

39. Nahrevanian H, Assmar M (2008) Cryptosporidiosis in immunocompromised patients in the Islamic Republic of Iran. J Microbiol Immunol Infect 41: 74-77. 
Citation: Ballani N, Shujatullah F, Khan HM, Malik A, Ali MSM, et al. (2012) Intestinal Protozoa in Immunosuppression: A Medical Hassle. J Bacteriol Parasitol 3:138. doi:10.4172/2155-9597.1000138

Page 5 of 5

40. Chan AW, MacFarlane IA, Rhodes JM (1989) Cryptosporidiosis as a cause of chronic diarrhoea in a patient with insulin-dependent diabetes mellitus. $\mathrm{J}$ Infect 19: 293.

41. Treviño-Pérez S, Luna-Castaños G, Matilla-Matilla A, Nieto-Cisneros L (1995) Chronic diarrhea and Cryptosporidium in diabetic patients with normal lymphocyte subpopulation. 2 case reports. Gac Med Mex 131: 219-222.
42. Wells GM, Gaijar A, Pearson TA, Hale KL, Shenep JL (1998) Brief report. Pulmonary cryptosporidiosis and Cryptococcus albidus fungemia in a child with acute lymphocytic leukemia. Med Pediatr Oncol 31: 544-546.

43. Kocoshis SA, Cibull ML, Davis TE, Hinton JT, Seip M, et al. (1984) Intestinal and pulmonary cryptosporidiosis in an infant with severe combined immune deficiency. J Pediatr Gastroenterol Nutr 3: 149-157. 